\title{
Peritoneal Dialysis in End-Stage Renal Disease Patients With Preexisting Chronic Liver Disease and Ascites
}

ROY G. MARCUS, M.D., JOSEPH MESSANA, M.D., RICHARD SWARTZ, M.D., Ann Arbor, Michigan

PURPOSE: Hemodialysis in patients with chronic liver disease and ascites may be complicated by intradialytic hypotension, limiting the amount of ultrafiltration and resulting in massive ascites. Successful maintenance peritoneal dialysis (PD) has not been previously reported as an alternative to hemodialysis in this population.

PATIENTS AND METHODS: Nine patients with chronic renal failure, chronic liver disease, and tense ascites prior to beginning $P D$ are described. All chronic PD catheters were placed percutaneously by the nephrology staff. Seven patients were maintained primarily on continuous ambulatory peritoneal dialysis, whereas two were on intermittent peritoneal dialysis.

RESULTS: PD catheters were placed without serious hemorrhage or bowel injury. PD provided adequate clearance and volume maintenance for each patient. Fifteen episodes of peritonitis occurred in 18 patient-years of $P D$. All episodes of peritonitis were successfully treated with intraperitoneal antibiotics without catheter removal. Only one patient had a decline in the serum albumin level of $0.5 \mathrm{~g} / \mathrm{dL}$ or more during the course of chronic PD. Three of the nine patients are still alive and on PD for durations of 18 to 24 months. One patient insidiously developed sclerosing peritonitis after 8 years on $P D$ and is now on hemodialysis, and another patient switched to hemodialysis because she was no longer able to care for herself or to manage her PD. Four patients died while maintained on PD; three deaths were due to complications of liver failure within the first 4 months of PD and the fourth was due to empyema after 4 years of PD.

CONCLUSION: PD can be used successfully to treat chronic renal failure in patients with chronic liver disease and ascites when the liver

From the Department of Internal Medicine, Division of Nephrology, University of Michigan, Ann Arbor, Michigan.

Requests for reprints should be addressed to Roy G. Marcus, M.D., Division of Nephrology, MSRB 2, Room 1560, 1150 West Medical Center Drive, Ann Arbor, Michigan 48109.

Manuscript submitted October 23, 1991, and accepted in revised form February 18, 1992. disease itself is not rapidly fatal. PD may be better tolerated than hemodialysis and perhaps should be the renal replacement treatment of choice in these patients.

$\mathbf{P}$ atients with chronic liver disease and ascites who require dialysis for acute or chronic renal failure pose difficult management problems. Hemodialysis in these patients may be complicated by intradialytic hypotension, limiting the amount of ultrafiltration and resulting in massive ascites [1-3]. These patients are also at high risk for gastrointestinal bleeding, which can be exacerbated by anticoagulation.

Peritoneal dialysis (PD) may have several distinct advantages in treating patients with chronic liver disease and ascites, including slow and continuous ultrafiltration using equilibration PD techniques, direct removal of ascitic fluid, and avoidance of anticoagulation. Despite these theoretic considerations, there are few reports of maintenance PD in such patients. Potential disadvantages that may have limited the use of PD in these patients include the fear of excessive bleeding following catheter placement, inefficient ultrafiltration and solute removal in the presence of massive ascites, and protein loss through the peritoneal membrane [4].

Nine patients with chronic liver disease and ascites have been treated successfully with maintenance $P D$ at our institution, and this report serves to describe these cases and review the pertinent literature.

\section{PATIENTS AND METHODS}

The records of the PD unit of the University of Michigan were reviewed, and all patients with both chronic renal failure and liver disease were identified. All patients who had evidence of chronic liver disease and ascites at the time of initiation of PD were included in this retrospective review. Ascites was defined by the presence of a fluid wave or shifting dullness on physical examination, or by evidence of ascites on abdominal computed tomographic (CT) scan or ultrasound. 


\section{TABLE I}

Patient Characteristics Prior to Starting Dialysis

\begin{tabular}{|c|c|c|c|c|c|c|c|c|}
\hline Patient & $\begin{array}{c}\text { Liver } \\
\text { Disease }\end{array}$ & $\begin{array}{c}\text { Renal } \\
\text { Disease }\end{array}$ & $\begin{array}{l}\text { Bilirubin } \\
\text { (mg/dL) }\end{array}$ & $\underset{(\mathrm{g} / \mathrm{dL})}{\text { Albumin }}$ & Ascites & $\begin{array}{c}\mathrm{H} / 0 \\
\text { Enceph }\end{array}$ & $\begin{array}{c}\text { Pugh } \\
(5-15)\end{array}$ & $\begin{array}{c}\text { Varices } \\
\text { Bleed }\end{array}$ \\
\hline 1 & ETOH, biopsy-proven cirrhosis & Small kidneys at presentation & 3 & 3.0 & Tense & No & 9 & Yes/No \\
\hline 2 & Biopsy-proven cirrhosis & Polycystic kidney disease & $<2$ & $>3.5$ & Tense & No & 7 & Yes/No \\
\hline 3 & Biopsy-proven cirrhosis & Polycystic kidney disease & $<2$ & 3.3 & Tense & No & 8 & No \\
\hline 4 & ETOH, small liver & FSGS & $<2$ & $>3.5$ & Tense & No & 7 & No \\
\hline 5 & ETOH & ? Hepatorenal syndrome & 2 & 1.8 & Tense & Yes & 12 & Yes/Yes \\
\hline 6 & Chronic hepatitis B & Small kidneys at presentation & $<2$ & 3.5 & Tense & No & 8 & Yes/Yes \\
\hline 7 & $E T O H$, small liver, history of SBP & Insulin-dependent diabetes mellitus & $<2$ & 2.2 & Tense & No & 9 & No \\
\hline 8 & Primary amyloidosis, hepatomegaly & Primary amyloidosis & $<2$ & 2.0 & Tense & No & 9 & No \\
\hline 9 & ETOH, biopsy-proven cirrhosis & ? Hepatorenal syndrome & 8 & 2.9 & Tense & Yes & 14 & Yes/Yes \\
\hline
\end{tabular}

$\mathrm{H} / 0 \mathrm{Enceph}=$ history of hepatic encephalopathy; Pugh $=$ Pugh modification score of the Child-Turcotte classification system [5]; Varices/bleed $=$ presence of esophageal varices/history of variceal bleeding; ETOH = alcohol-related liver disease; FSGS = focal and segmental glomerular sclerosis; SBP = spontaneous bacterial peritonitis.

Nine patients were identified who met these criteria among the 465 patients treated in our chronic PD program between 1980 and 1990. Table I shows the etiology of liver disease and renal disease in our patients. Table II shows the clinical characteristics of liver disease in our patients including the Pugh modification score of the Child-Turcotte classification system, which describes the severity of cirrhosis [5]. All nine patients had a history of tense ascitos prior to initiating PD. Seven patients were maintained primarily on continuous ambulatory peritoneal dialysis, whereas two were on intermittent peritoneal dialysis.

\section{RESULTS}

\section{Insertion of PD Catheter}

All chronic PD catheters were placed percutaneously in a paramedian location by the nephrology staff using a stainless steel trochar technique before 1985 , and using a guide wire and peel-away sheath technique after 1985 [6]. There were no serious hemorrhagic complications or bowel injuries. Five

\begin{tabular}{|c|c|c|c|c|c|}
\hline \multicolumn{6}{|c|}{$\begin{array}{l}\text { TABLE II } \\
\text { Adequacy and Duration of Dialysis }\end{array}$} \\
\hline Patient & Modality & $\begin{array}{l}\mathrm{KT} / \mathrm{V}^{*} \\
\text { (per wk) }\end{array}$ & $\begin{array}{l}\text { Equilibration Test } \\
\left(3-\mathrm{h} \mathrm{D} \text { urea } / \mathbf{P}_{\text {urea }}\right)\end{array}$ & $\begin{array}{c}\text { Duration of } \\
\text { Peritoneal Dialysis }\end{array}$ & Outcome \\
\hline 1 & CAPD & 0.9 & - & $4 y$ & Died-empyema \\
\hline 2 & CAPD & 1.3 & $91 \%$ & $8 y$ & Sclerosing peritonitis, changed to $H D$ \\
\hline 3 & CAPD & 1.6 & $78 \%$ & $18 \mathrm{mo}$ & Still on CAPD \\
\hline 4 & CAPD & 1.3 & - & $2 y$ & Still on CAPD \\
\hline 5 & CAPD & 2.7 & $80 \%$ & $2 y$ & Still on CAPD \\
\hline 6 & CAPD & 1.2 & - & $2 \mathrm{mo}$ & Died-liver failure \\
\hline 7 & CAPD & $1.5-1.7$ & $82 \%$ & $9 \mathrm{mo}$ & Inability to care for herself, changed to $\mathrm{HD}$ \\
\hline 8 & IPD & - & - & $4 \mathrm{mo}$ & Died-cardiac arrest \\
\hline 9 & IPD & - & - & $3 \mathrm{mo}$ & Died-hepatic encephalopathy \\
\hline
\end{tabular}

$D_{\text {urea }} / P_{\text {urea }}=$ dialysate urea/plasma urea; $C A P D=$ continuous ambulatory peritoneal dialysis; $/ P D=$ intermittent peritoneal dialysis; $\mathrm{HD}=$ hemodialysis.

${ }^{*} \mathrm{KI} I / \mathrm{V}=7\left(0.9 \times \mathrm{DDDV}+1.44 \times \mathrm{C}_{\mathrm{r}}\right) /$ /total body water (7]. The dally dialysate drain volume (DDDV) was estimated as the prescribed exchange volume plus $500 \mathrm{~mL}$ for each exchange as an estimate of ultrafiltration. This volume was muttiplied by 0,9 to estimate the equilibration of urea at 4 to 5 hours average exchange time. Residual renal function ( $\mathcal{C}_{r}$ ) is known for Patient 5 only. 
patients had elevated prothrombin times (14.1, 14.6, 15.1, 16.3, and 26 seconds), and bleeding times were not checked routinely prior to catheter insertion. Eight catheters were curled, double-cuff devices, and one was a double-cuff straight catheter. Due to immediate dialytic needs, six catheters were used for low volume, short intraperitoneal dwell time dialysis on the day of insertion. One of these six patients (Patient 7) developed a small leak at the insertion site that resolved after 2 days without PD. There were no leaks in the three patients whose catheter use began after a 7- to 10-day break-in period. Patient 7 had unsuspected spontaneous bacterial peritonitis with Klebsiella pneumonia at the time of catheter insertion. The catheter was left in place, and the infection was successfully treated with intraperitoneal antibiotics.

\section{Duration of PD}

Table II shows the duration of PD and the reason for termination for each patient. Three of the nine patients are still alive and on PD with durations of 18 to 24 months. Two patients switched to hemodialysis. One of these patients insidiously developed sclerosing peritonitis after 8 years on PD. The other patient switched to hemodialysis because she was no longer able to care for herself or to manage her PD, even though her PD course had been medically uncomplicated. Incidentally, while on hemodialysis, she continued to use her chronic PD catheter for intermittent drainage of symptomatic ascites. Four patients died while maintained on PD; three of these deaths were due to complications of liver failure within the first 4 months of treatment and the fourth was associated with empyema and possibly related to chronic PD after 4 years of treatment.

\section{Adequacy of Dialysis}

All patients were maintained without uremic symptoms while on PD except Patient 2 when she developed sclerosing peritonitis. Blood urea nitrogen (BUN) ranged from 40 to $70 \mathrm{mg} / \mathrm{dL}$ in seven patients. BUN was 80 to $95 \mathrm{mg} / \mathrm{dL}$ in Patient 5 and was less than $70 \mathrm{mg} / \mathrm{dL}$ in Patient 2 until she developed sclerosing peritonitis when her BUN increased to $125 \mathrm{mg} / \mathrm{dL}$ and necessitated switching to hemodialysis. Table II lists the weekly urea index shown as $\mathrm{KT} / \mathrm{V}(\mathrm{K}=$ clearance of urea; $\mathrm{T}=$ time of dialysis; $\mathrm{V}=$ volume of distribution of urea) for each patient [7]. Several patients had residual urine output; however, only Patient 5 had a 24-hour urine collection to quantify the residual renal function $\left(\mathrm{C}_{\mathrm{r}}\right)$, and thus the $\mathrm{KT} / \mathrm{V}$ calculations in the other patients may underestimate the total clearance. Four patients had 3-hour peritoneal equilibration tests to assess their peritoneal transport kinetics. The ratio of dialysate urea to plasma urea $\left(D_{\text {urea }} /\right.$ $P_{\text {urea }}$ ) ranged from $78 \%$ to $91 \%$ except in Patient 2 after the onset of sclerosing peritonitis, when her $\mathrm{D}_{\text {urea }} / \mathrm{P}_{\text {urea }}$ decreased from $91 \%$ to $10 \%$, with the average 3-hour $\mathrm{D}_{\text {urea }} / \mathrm{P}_{\text {urea }}$ in our program averaging $0.81 \pm 0.08$ (unpublished data). We have not been able to obtain a peritoneal equilibration test on $\mathrm{Pa}$ tient 4 since he is a prison inmate, and the other four patients either died too early in the course to assess $\mathrm{KT} / \mathrm{V}$ adequately or died during the period prior to regular $\mathrm{KT} / \mathrm{V}$ and peritoneal equilibration test evaluations.

Hematocrit, another marker of dialysis adequacy, was less than $30 \%$ in five patients at the time of PD initiation. One of these patients had a increase from $26 \%$ to $33 \%$ after starting PD, and the others had stable hematocrits without the need for transfusions. Hematocrits were also stable in those patients who began with a hematocrit greater than $30 \%$.

\section{Pleural Effusion}

Two patients developed large chronic right pleural effusions. A radiolabeled peritoneogram in $\mathrm{Pa}$ tient 9 showed that peritoneal fluid flowed into his right pleural space. A similar study was not done in Patient 1. Patient 1 died secondary to a right empyema. Patient 9's death was unrelated to his pleural effusion.

\section{Hernia}

Patient 5 had an umbilical hernia at the time of catheter insertion, which was repaired 3 months later. Three patients developed hernias after beginning PD. Patient 2 developed an incisional hernia, which was repaired. Patient 4 developed an umbilical hernia, which improved with a decrease in exchange volume. Patient 9 developed a large umbilical hernia, which could not be repaired secondary to his poor general condition. All hernia repairs were successful, no hernias recurred, and patients continued with chronic PD therapy.

\section{Peritonitis}

There were 15 episodes of peritonitis in a total of 18 patient-years of $P D$. Seven infections were due to coagulase-negative staphylococci, one was due to a coagulase-positive staphylococci, four were due to Esherichia coli, and one due to a nonspecified gram-negative rod. Two infections were treated without obtaining a culture prior to initiation of antibiotic therapy. Seven infections required inpatient hospitalizations because the patients were believed to be too ill for outpatient management; how- 


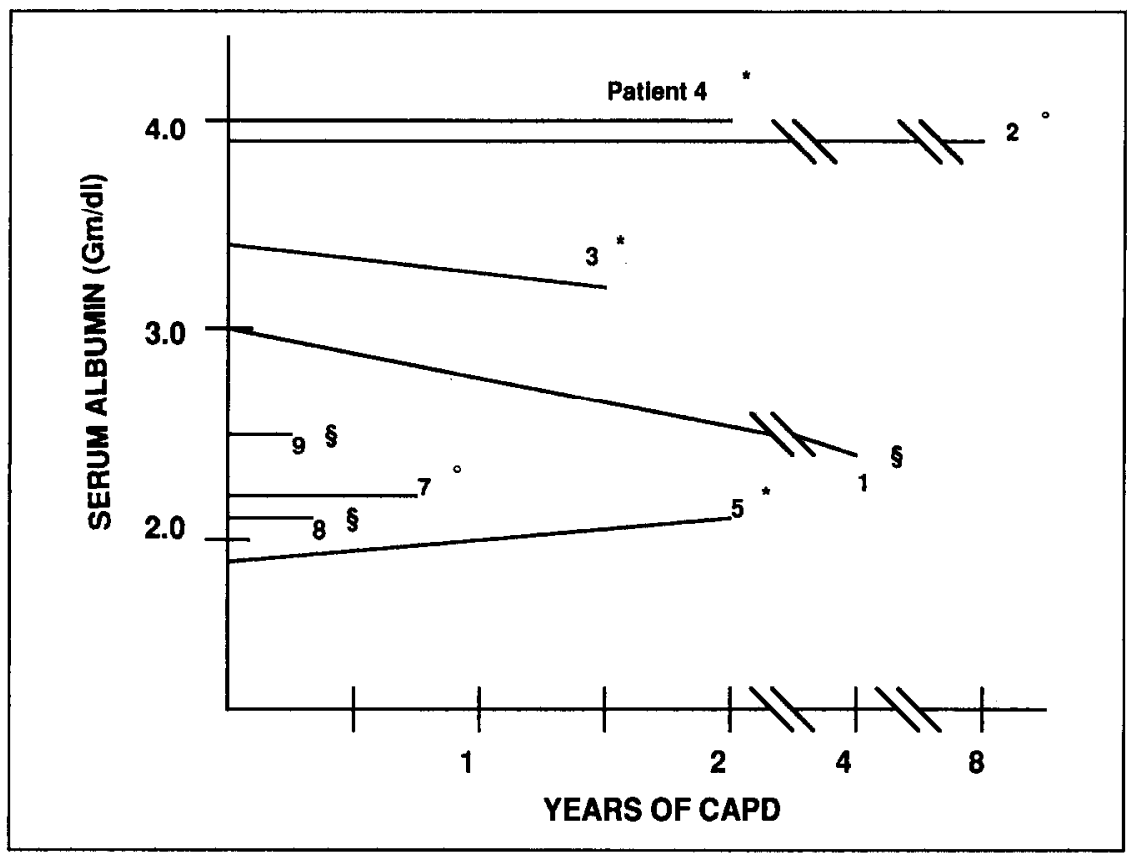

Figure 1. End point status: *Alive; ${ }^{\circ}$ Changed to hemodialysis; §Died.

ever, no patient needed care in the intensive care unit. All episodes were successfully treated with intraperitoneal antibiotics without catheter removal. There were no episodes of hepatic encephalopathy associated with peritonitis episodes.

\section{Hypoalbuminemia}

Figure 1 shows the course of serum albumin in eight of nine patients, excluding Patient 6 who survived only 2 months. Only one patient had a decrease in the serum albumin level of $0.5 \mathrm{~g} / \mathrm{dL}$ or more during the course of chronic PD. In all other cases, the serum albumin level remained stable through courses ranging from 4 months to 8 years. Dry weight, another indicator of nutritional adequacy, was stable or increased in all patients while maintained on PD, except for Patient 1 who lost 40 pounds in the 6 months prior to his death after having a stable weight for 3.5 years.

\section{COMMENTS}

Acute and chronic renal failure frequently complicate chronic liver disease. Although hypotension is frequent during hemodialysis in these patients [1-3], it is surprising that successful maintenance PD has not been reported as an alternative to hemodialysis in this population. The successful use of acute PD has been described in case reports of patients with chronic liver disease and in patients with fulminate acute liver disease [8-10]. However, the largest series of acute PD in patients with liver disease had discouraging results. All of the 20 cirrhotic patients died prior to hospital discharge, and only six of the 50 patients with fulminate acute liver disease survived [1]. This study also described five cirrhotic patients with acute renal failure treated with hemodialysis, all of whom died. PD has been used to treat noncirrhotic end-stage renal disease patients with hemodialysis-related ascites. These patients also have frequent hypotension during hemodialysis; however, they do not have liver disease or portal hypertension [11-14].

We have successfully utilized maintenance $P D$ in nine patients with chronic renal failure and chronic liver disease complicated by ascites. All of our patients had their peritoneal catheters placed percutaneously at the bedside. Although cirrhotic patients are potentially at greater risk of hemorrhagic complications secondary to the combination of abdominal wall varices, uremic platelet dysfunction, and clotting factor deficiency, we encountered no serious hemorrhagic complications. We also had minimal problems with leakage of dialysate despite early utilization of the catheters. Similar results have been reported for placement of stiff acute PD catheters in cirrhotics, although most of these previous reports have described catheters placed for short-term ultrafiltration and peritoneal reinfusion of ascitic fluid in patients with massive ascites with or without uremia $[1,9,10,15-18]$.

In our series, five of nine patients survived on $P D$ for at least 18 months with good control of uremic symptoms and volume status. Three of these patients are currently doing well on PD. These good 
results occurred despite low weekly clearances of urea, as measured by the KT/V calculations $[19,20]$. These patients were treated before we used kinetic analysis to help determine our PD prescriptions. Since the patients appeared to be clinically well dialyzed on their $\mathrm{PD}$ regimens using primarily $1.5-\mathrm{L}$ exchanges, we did not increase their exchanges to 2 L. Furthermore, the calculated $\mathrm{KT} / \mathrm{V}$ may have substantially underestimated the amount of total clearance for these patients since residual renal function was not measured [19].

The survival of our patients compares favorably with the expected survival of cirrhotic patients in general. The Pugh modification score of the ChildTurcotte classification for our patients' liver disease is shown in Table II. Patients with a score between 7 to 9 have been reported to have an $80 \% 1$ year survival rate, and patients with a score greater than nine have a $45 \%$ 1-year survival rate [5]. However, these survival rates are in patients without chronic renal failure, and renal failure likely imposes a substantial disadvantage to survival overall. In addition, three of our patients had a history of hemorrhage from esophageal varices, a strong risk factor for early mortality in chronic liver disease [21-23]. Two of these patients survived for only 2 to 3 months after beginning PD.

The rate of peritonitis in our patients, one episode every 1.2 patient-years, is similar to that of previous reports for PD patients in general [24]. Although spontaneous bacterial peritonitis is a well-known precipitator of hepatic encephalopathy, our patients did not develop hepatic encephalopathy during 15 episodes of $\mathrm{PD}$-associated peritonitis. This difference may have been due to early diagnosis of peritonitis in PD patients, to the intermittent peritoneal lavage with each dialysis fluid exchange, or to inherent pathogenic differences between PD peritonitis, a common skin organism infection from an external source, and spontaneous bacterial peritonitis, a serious enteric infection from internal sources. In addition, it is possible that PD removes some of the toxin that causes hepatic encephalopathy, akin to reports of temporary improvement in some patients with hepatic encephalopathy following high-permeability hemodialysis $[25,26]$. Also, the patient who had spontaneous bacterial peritonitis found unexpectedly at the time of catheter placement did well with intraperitoneal antibiotics and ongoing PD without catheter removal.

Only two of our patients had complications of PD that contributed to the death of one patient and led to discontinuation of chronic PD in the other. One patient had a chronic pleural effusion that became infected, leading to his death after 4 years of PD. Pleural effusions are reported to occur in $1.6 \%$ of PD patients without pre-existing liver disease [27] and are common in cirrhotic patients not on dialysis [28]. Although a large abdominal volume secondary to ascites accumulation and PD fluid could lead to high intra-abdominal pressure and hence an increased tendency for translocation of fluid through small holes in the diaphragm, this patient did not have tense ascites while on PD. The other patient developed sclerosing, calcifying peritonitis. She had only one episode of peritonitis during her 8 years of PD. Whether portal hypertension in addition to chronic peritoneal exposure to hypertonic solutions played a pathogenic role in the development of sclerosing peritonitis is unknown.

In summary, this report demonstrates that PD can be successfully used to treat end-stage renal disease in patients with chronic liver disease and ascites. PD may be better tolerated than hemodialysis, and perhaps should be the renal replacement treatment of choice in these patients since it eliminates the need for anticoagulation, controls ascites accumulation, may prevent serious complications from spontaneous bacterial peritonitis, and can often be associated with excellent long-term survival and sustained nutrition in patients whose liver disease itself is not rapidly fatal.

\section{REFERENCES}

1. Wilkinson SP, Weston MJ, Parsons V, Williams R. Dialysis in the treatment of renal failure in patients with liver disease. Clin Nephrol 1977; 8: 287-92.

2. Gandhi VC, Leehey DJ, Stanley MM, et at. Peritoneo-venous shunting in patients with cirrhotic ascites and end-stage renal failure. Am J Kidney Dis 1985 6: 185-7

3. Yen ML, Stewart EH. Peritoneo-venous shunt for ascites associated with maintenance dialysis. Clin Nephrol 1977; 8: 446-8.

4. Epstein M. Renal disorders in liver disease. In: Suki WN, Massry SG, editors Therapy of renal diseases and related disorders, 2nd edition. Norwell, Massachusetts: Kluwer Academic, 1991: 477-93.

5. Infante-Rivard C. Esnaola S, Villeneuve JP. Clinical and statistical validity of conventional prognostic factors in predicting short-term survival among cirrhotics. Hepatology 1987; 7: 660-4.

6. Swartz R, Messana J, Raynolds J, et al. Curled catheter: dependable device for percutaneous access. Peritoneal Dialysis International 1990; 10: 231-6.

7. Blake PG, Sombolos K, Abraham G, et al. Lack of correlation between urea kinetic indices and clinical outcomes in CAPD patients. Kidney Int 1991; 39: $700-6$.

8. Clark F, O'Leary JP. Survival associated with hepatorenal syndrome. South Med J 1979; 72: 87-90.

9. Schroeder ET, Numann PJ, Chamberlain BE. Functional renal failure in cirrhosis. Recovery after portacaval shunt. Ann Intern Med 1970; 72; 923-8.

10. Ellis D, Avner ED, Starzl TE. Renal failure in children with hepatic failure undergoing liver transplantation. J Pediatr 1986; 108: 393-8.

11. Gluck Z, Nolph KD. Ascites associated with end-stage renal disease. Am $J$ Kidney Dis 1987; 10: 9-18.

12. Gotloib L, Servadio $C$. Ascites in patients undergoing maintenance hemodialysis. Report of six cases and physiopathologic approach. Am J Med 1976; 61 465-70.

13. Ing TS, Daugirdas JT, Popli S, et al. Treatment of refractory hemodialysis 
ascites with maintenance peritoneal dialysis. Clin Nephrol 1981; 15: 198-202. 14. Rubin J, Kiley J, Ray R, McFarland S, Bower J. Continuous ambulatory peritoneal dialysis: treatment of dialysis-related ascites. Arch Intern Med 1981; 141: 1093-5.

15. Assadi FK, Gordon D, Kecskes SA, John E. Treatment of refractory ascites by ultrafiltration-reinfusion of ascitic fluid peritoneally. J Pediatr 1985; 106 : 943-6.

16. Hwang ER, Sherman RA, Mehta $S$, et al. Dialytic ascitic ultrafiltration in refractory ascites. Am J Gastroenterol 1982; 77: 652-4.

17. Levy VG, Pauleau N, Opolon P, Caroli J. Treatment of ascites by reinfusion of concentrated peritoneal fluid-review of 318 procedures in 210 patients. Postgrad Med J 1975; 51 ; 564-6.

18. Feldman J, Adler AJ, Friedman EA, Berlyne GM. Extracorporeal recirculating ascites dialysis in combined hepatic and renal failure. Trans Am Soc Artif intern Organs 1981; 27: 563-5.

19. Lysaght MJ, Pollock CA, Hallet MD, Ibels LS, Ferrell PC. The relevance of urea kinetic modeling to CAPD. Trans Am Soc Artif Intern Organs 1989; 35: 784-90.

20. Keshaviah PR, Nolph KD, Van Stone JC. The peak concentration hypothesis: a urea kinetic approach to comparing the adequacy of continuous ambulatory peritoneal dialysis (CAPD) and hemodialysis. Peritoneal Dialysis International
1989; 9: 257-60.

21. Christensen $E$, Krintel JJ, Hansen SM, Johansen JK, Juhl E. Prognosis after the first episode of gastrointestinal bleeding or coma in cirrhosis. Survival and prognostic factors. Scand J Gastroenterol 1989; 24: 999-1006.

22. Jansen PL. Life expectancy in liver cirrhosis after the first variceal hemorrhage: how can survival be improved? Scand J Gastroenterol 1990; 178 . 106-10.

23. Graham DY, Smith JL. The course of patients after variceal hemorrhage. Gastrocnterology 1981; 80: 800-9.

24. National CAPD Registry of the NIH. Characteristics of participants and selected outcome measures for the period January 1, 1981 through August 31 1987.

25. Denis J, Opolon P, Nusinovici V, Granger A, Darnis F. Treatment of encephalopathy during fulminant hepatic failure by haemodialysis with high permeability membrane. Gut 1978; 19: 787-93.

26. O'Grady JG, Williams R. Management of acute liver failure. Schweiz Med Wochenschr 1986; 116: 541-4.

27. Nomoto $Y$, Suga $T$, Nakajima $K$, et al. Acute hydrothorax in continuous ambulatory peritoneal dialysis-a collaborative study of 161 centers. Am J Nephrol 1989; 9: 363-7.

28. Chetty KG. Transudative pleural effusions. Clin Chest Med 1985; 6: 49-54. 